\title{
A Qualitative Analysis of Korean Students' Awareness of Motivational Macro Strategies
}

\author{
Chris Kobylinski $^{1} \&$ Michael Heinz ${ }^{2}$ \\ ${ }^{1}$ Foreign Language Education, Hanguk University of Foreign Studies, Seoul, Republic of Korea \\ ${ }^{2}$ Graduate School of Interpretation and Translation, Hanguk University of Foreign Studies, Seoul, Republic of \\ Korea \\ Correspondence: Chris Kobylinski, Foreign Language Education, Hanguk University of Foreign Studies, 107 \\ Imun-ro, Dongdaemun-gu, Seoul 02450, Republic of Korea. Tel: 82-10-9129-0449.
}

Received: August 28, 2018

Accepted: September 10, 2018

Online Published: September 17, 2018

doi:10.20849/jed.v2i3.469

URL: https://doi.org/10.20849/jed.v2i3.469

\begin{abstract}
Motivation remains a topic of great importance in the field of EFL. Numerous studies have highlighted the linkage between the use of motivational strategies and student achievement in foreign language acquisition. In 2017 a study carried out by Heinz and Kobylinski found significant differences between the ways in which Korean students rated the use of motivational strategies by native English-speaking English teachers and native Korean speaking English teachers. These differences were explored primarily through the use of a 47 question survey utilizing a 5-point Likert scale and some limited qualitative interviews. As the survey provided strategies for comparison, the question arose whether students recalled such differences due to prompting and how a more open-ended investigation might better explain these findings. As such open-ended interviews were carried out with 21 Korean students whose backgrounds were similar to the students in the previous study. The results not only confirmed previous findings but provided considerable context as to why strategy implementation differs between the two groups. The most significant differences described were related to creating a pleasant classroom environment and familiarizing students with L2 related values. Interviewees described a high stress environment within the Korean educational system and suggested that differences between the two groups were more pronounced when native English-speaking English teachers were teaching in an international or American setting.
\end{abstract}

Keywords: ELT, EFL, motivation, motivational strategies, Dornyei, South Korea

\section{Introduction}

Motivation has been a key issue and reoccurring problem in EFL (English as a Foreign Language) for a very long time (Dornyei \& Kubanyiova, 2014; Ushioda, 2013). Many famous names and studies have tackled this issue in various ways and for good reason. EFL teachers face many obstacles and difficulties, but none may be more difficult to overcome than a lack of student motivation. Motivating students in an EFL classroom is constantly highlighted as one of the biggest difficulties in ELT (English Language Teaching), outranking even the selection of teaching methodology, subject matter proficiency, and textbook and curriculum guide usage (Veenman, 1984). While motivation itself is universal, it does have some unique issues in various countries.

This paper is a follow up to a previous study that looked at student perspectives on the motivational strategies of Native English Speaking (hereafter labeled NES) English Teachers and Native Korean Speaking (hereafter labeled NKS) English Teachers in South Korea. The previous study conducted by this paper's authors Heinz and Kobylinski (2017) surveyed 102 undergraduate and 49 graduate students in a Korean university using a survey that was based on a survey that was created by Cheng and Dornyei (2007) for a study of 387 Taiwanese English teachers. That study found some vast differences between the motivational strategies that were used by NKS and NES teachers.

The purpose of this study is to further examine the student perspectives through the use of qualitative group interviews, in order to see if any additional insight could be found that could shed light on the perceived differences. While the surveys gave an overall view, they didn't really pinpoint why the motivational strategies were chosen or precisely how they were employed by either group. In addition, because the students answered 
the survey based on a lifetime of experience, it was impossible to see if their opinions were coming from unique experiences or reflective of the general experiences that apply to most students. The hope was that the interviews would clarify the students' opinions and give further insight into how and why the motivational strategies were used by each group and help to answer the following research question: What types of motivational strategies were employed by NES and NKS teachers and did those strategies have a positive influence on motivating students?

\section{Literature Review}

The previous study that inspired this study was heavily based on Dornyei and his model of motivation. Dornyei's model, the L2 Motivational Self System, consists of three unique components, the Ideal L2 self, the Ought-to L2 self, and the L2 learning experience (2009). Dornyei defines the Ideal L2 self as "the L2 specific facet of one's ideal self;" the Ought-to L2 as "the attributes that one believes one ought to possess in order to avoid possible negative outcomes;" and the L2 learning experience as "situation-specific motives related to the immediate learning environment and experience (2009)".

Models and theories of motivation are important, but more important to most EFL teachers is how motivation relates to language achievement and student success. In addition to his model, Dornyei also spoke of motivation as an indicator of achievement and success. Dornyei asserts that, "Motivation is one of the main determinants of second/foreign language achievement (Dornyei, 1994, p. 273).

It is important to consider not only student motivation, but also how the motivational strategies that are utilized by teachers influence student motivation. Studies have found that the motivational strategies that teachers employ can influence student motivation. (Dornyei, 1994; Dornyei, 1998; Dornyei, 2001a; Dornyei, 2001b; Bravo, Intriago, Holguin, Garzon, \& Arcia, 2017). While it has been proven that the motivational strategies that teachers use influence the motivation of the students, findings in a study conducted by Jacques (2001) found that significant discrepancies can exist between how highly teachers rate the successful implementation of motivational strategies and how students rated the success of that implementation. Overall students rated activities lower than teachers did.

There are a few studies that directly examine the motivational strategies that are used in the South Korean context. The relationship between the motivational strategies used by teachers and the language learning motivation of students was explored by Guillautaux and Dornyei (2008). This study used a classroom observation instrument called the MOLT (motivation orientation of language teaching) and questioners in a study of 27 teachers and 1,300 students to show the clear connection between the motivational strategies used by teachers and the language learning motivation of the students. Papi and Abdollahzadeh (2012) replicated this study outside of Korea and had similar findings, but added that more studies need to focus on university students and teachers because of the unique context of tertiary settings.

A few studies have shown some issues with the lack of motivational strategies utilized by teachers in Korea. A study of secondary school teachers done by Guillautaux (2013) showed some problems that were unique to Korea. Guillautaux found that almost all of the motivational strategies were underused by Korean teachers and claimed that this was "likely to stem from contextual constraints or from a lack of skills." Another study about Korean secondary school teachers by Maeng and Lee (2015) stated that "teachers did not effectively incorporate motivational strategies to promote student motivation."

While some might find these observations shocking, the observations are in line with what was found during the original study. Heinz and Kobylinski (2017) through the use of a survey as described earlier found that Korean students rated NKS teachers more highly in terms of motivational macro strategies in the following areas: regularly reminding students that the successful mastery of English is beneficial to their future, and encouraging students to select specific, realistic and short-term learning goals for themselves. However, on the remainder of 47 items NES teachers received higher scores with the most significant differentials being in: creating opportunities so that students can mix and get to know each other better, encouraging student participation by assigning group activities that require involvement from each participant, bringing in and encouraging humor and laughter frequently in class, making sure that grades reflect not only the students achievement but also the effort they have put into the task, creating a supportive and pleasant classroom climate where students are free from embarrassment and ridicule, and encouraging students to share personal experiences and thoughts as a part of the learning tasks.

Another study conducted by Yeo (2017) showed some interesting findings that both support and provide context for the findings of Heinz and Kobylinski. Yeo found that Korean instructors were more concerned about encouraging students to set realistic learning goals and the students surveyed by Heinz and Kobylinski also 
found that students thought NKS speakers were better at this. Yeo also claimed that NES instructors were more concerned with making a pleasant classroom environment and the data collected by Heinz and Kobylinski also backed this up. One macro strategy showed some contrast between how the students felt and what teachers reported. Yeo reported that Korean instructors were more concerned about the L2 culture, but the students surveyed by Heinz and Kobylinski rated the NES teachers higher for that category.

These findings, especially the findings about the lack of motivational strategies used in the South Korean context lead to this follow-up study. The researchers wanted to see if group interviews with students could provide some first-hand insight into how motivational strategies were or weren't used in the classroom. Also, the researchers wanted to see if the differences between NKS and NES teachers were the result of the teaching environment or some other factors.

\section{Subjects}

\subsection{Graduate School Subjects}

Six students chosen for the group interviews were graduate school students majoring in interpretation and translation from Korean to English and vice versa. All of these students possess Korean as their mother tongue but are highly proficient bilinguals and many of them grew up in nations other than Korea but all of them had lived at least part of their lives in Korea. These students were more likely than the undergraduate students to have some experience learning English or learning subject matters in English from NES teachers in an international setting which they most frequently described as an "American" setting even if it occurred outside of the United States. One student spent at least ten years in an "American" school in Shanghai during her formative years.

\subsection{Undergraduate School Subjects}

Eighteen students chosen for the group interviews came from undergraduate Communicative English classes, which are credit-bearing classes mainly designed and made up of first year students. The classes are multi-skill classes designed to prepare students to study in an English language classroom. Five groups consisting of three students per group were selected out of a pool of volunteers to participate in the group interviews. These undergraduate students were more likely to have encountered NES teaching in the Korean education system but it should be noted that many of these students had also spent some time studying abroad albeit for a generally smaller number of years than the graduate school students interviewed.

\section{Methodology}

In order to broaden the interpretation of the findings from the previous study by Heinz and Kobylinski (2017) a holistic single case study with multiple units of analysis was conducted through qualitative analysis of semi-structured interviews with Korean students in which questions were asked with a minimum of prompting initially to determine which macro strategies were most sustained in the memories of students. Prior to the interviews the following questions were selected as the initial prompts to acquire data from the students:

Please describe in detail the motivational strategies that you feel best characterize the teaching activities carried out by Native English speakers in classrooms oriented towards learning English?

Please describe in detail the motivational strategies that you feel best characterize the teaching activities carried out by Native Korean speakers in classrooms oriented towards learning English?

In addition to these two questions a selection of motivational strategies identified in the previous study as showing great variance between NES teachers and NKS teachers were selected and subjects were asked about the following only if a discussion of these strategies was not included in their answers to the initial prompt. The standout motivational strategies that showed significant differences were queried as follows:

Did NES/NKS teachers bring in and encourage humor and laughter frequently in your class?

Did NES/NKS teachers create opportunities so that students can mix and get to know each other better (e.g., group work, game-like competition)?

Did NES/NKS teachers make sure grades reflect not only the students' achievement but also the effort they have put into the task?

Did NES/NKS teachers create a supportive and pleasant classroom climate where students are free from embarrassment and ridicule?

Did NES/NKS teachers bring various authentic cultural products (e.g., magazines, newspapers or song lyrics) to class as supplementary materials? 
Did NES/NKS teachers make clear to students that the important thing in learning a foreign language is to communicate meaning effectively rather than worrying about grammar mistakes?

Did NES/NKS teachers try to be herself/himself in front of students without putting on an artificial "mask", and shares with them his/her hobbies, likes and dislikes?

Did NES/NKS teachers regularly remind students that the successful mastery of English is beneficial to their future (e.g., getting a better job or pursuing further studies abroad)?

After the interviews were conducted the data was analyzed by coding the data, identifying themes, ordering all the codes and themes and finally attempting to describe the overall consistent findings within and interpret their significance particularly with regards to the previous study. Relative outliers within the data were also considered but the primary focus of the coding was to determine what if any themes and codes showed consistency across the various groups to be certain of the data's reliability.

\section{Findings}

Discussions with students led to several important findings. Overall it was clear in the interviews that students felt that there were significant differences between NES and NKS teachers even if sometimes they could not clearly articulate those differences. Students used expressions like "totally different" or approached the question of differences as though the differences were rather obvious and, in some instances, took the question of differences as a joke. When pressed to clarify those differences many findings were uncovered.

One of the most frequently mentioned differences in terms of differing macro strategies related to motivation was creating a pleasant classroom environment. Students described NKS teacher-led classrooms as high-pressure environments in which social comparison was built into the system. When pressed for direct statements of social comparison students could not recall any but instead repeatedly described a tiered classroom assignment structure in which students were grouped in five different sections based entirely on test performance. Students described themselves as being constantly aware of this comparison although specific statements of comparisons could not be recalled.

On the other hand, classes led by NES teachers whether within the Korean system or in an international/American setting were not described as excelling in terms of creating a pleasant classroom environment but efforts to do so were easy for the students to recall and to provide examples for. Students talked about the use of humor in the classroom and the absence of social comparison. One student fondly recalled an Australian teacher with a particularly pronounced use of sarcasm which the student found very novel given the low prevalence of sarcasm within Korean culture. When queried directly about humor in NKS classrooms this question often drew forth laughter and explicit statements regarding its absence though two students said some of their NKS teachers were funny but didn't feel that their humor carried over into being an active aspect of their classrooms.

Another point of interest in which sharp differences were described was familiarizing students with L2 related values. Herein both groups did make efforts to utilize cultural contents within the classroom but the types of contents selected differed greatly. NKS teacher-selected materials were described as being bland, neutral and relatively ubiquitous such as analysis of western pop music within the mainstream of Korean culture. An example of this is one student recalling an in-class translation of the pop group West Life's lyrics. Alternatively, students were able to recall specific instances in which NES teachers utilized cultural contents best described as critical contents or subversive materials. One student felt that the literature chosen by her NES teachers was instrumental in the development of her own critical faculties. Another student spoke deeply about the shock she felt when an NES teacher played Pink Floyd's the Wall and analyzed the song's profoundly anti-establishment message. Students displayed uniform opinions that the NES teachers' attempts to familiarize students with L2 related values were more engaging. This may provide context for why in Yeo's study (2017) NKS instructors rated familiarizing students the cultural background of the L2 significantly higher but students in the previous study by Heinz and Kobylinski (2017) rated NES instructors' implementation of this strategy more highly. This could mean that while NKS teachers believe in the importance of L2 cultural materials their selection process may differ substantially.

In addition to these descriptions of significant differences students made statements suggesting that NES teachers were more likely to explicitly employ the following motivational macro strategies in class: promoting learners self-confidence through direct positive feedback, making the learning tasks stimulating by varying up curriculum materials, proper teacher behavior such as displaying passion and enthusiasm, and promoting learner autonomy through group work that depended on cooperation instead of the segmenting of tasks as the group 
work assigned by NKS teachers was frequently described. However, despite the seemingly higher praise afforded to NES teachers, the students never questioned their sense of motivation in NKS classrooms. Rather they explained that a profound sense of external pressure kept them focused within those classrooms. Moreover, students suggested multiple times that there was little room for various classroom-based macro strategies in the NKS classroom because the systematic focus on test scores would render such strategies irrelevant. Students repeatedly stated that the implicit and explicit values provided by family and society provided them with pressure that they equated with motivation even when they were learning in NES classrooms within the Korean system or within International/American school systems. Of note here is the fact that students equated this pressure with a sense of motivation but alternatively described this type of pressure with a sense of obvious dread. They described school as a place that they "survived" and used expressions to describe the environment such as "so hard," "you know that you need to do more," and "crazy." Yet when speaking of NES teachers created environments they tended to describe the systems as being innately less stressful but in the case of international/American settings several students described a drive to compete with the native-speaking peers or to perform well on tests such as the SATs. These described pressures which they equated with motivation seemed to come from outside of the classroom but the students seemed to be very mindful of the existence of such pressure.

In some instances, students described NES teachers working within the Korean system as being tools that followed the broader curriculum strategies within the Korean system. The input of these NES teachers was described as lacking in control or power related to the curriculum planning and testing to such an extent that their purpose within the classroom made them something of a living piece of cultural content rather than an actual teacher. They were described as functioning like the audio recordings normally used for the purpose of English learning. More generally NES teachers described as teaching within the Korean system were less likely overall to be described as implementing significantly different motivational macro strategies within the classroom though differences were evidenced. Most frequently the description of significant motivational macro strategy usage was ascribed to NES teaching in an international/American school system.

\section{Discussion}

It was interesting to see that none of the quantitative findings within the first study were contradicted by this study's qualitative data. Rather with open questions and no significant prompting students painted a fundamentally similar portrait of the remembered differences between the NKS and NES teachers they had experienced. Reasonably speaking the qualitative data portrayed a more severe sense of differences and tended towards a somewhat bleak view of the Korean educational system though less from the perspective of the system's failures and more from a perspective of the overriding sense of pressure derived from familial and societal sources. It was interesting to listen to students struggle to pin down explicit statements that led them to inculcate a sense of pressure that they equated with motivation though the students were adamant that such pressure was both real and prevalent throughout their experiences within the Korean system. Nearly all students stated that family put pressure on them to succeed in school. That this followed them into NES classrooms in an international/American setting, though to a lesser degree, is a finding of some significance.

Overall many students struggled to identify motivational macro strategies when given a rather open prompt such as "What motivational strategies do you think that Korean teachers used when teaching you English?" And when asked more pointed questions like "Do you recall the use of humor in your classes with Korean teachers," students did not seem to equate many of the motivational macro strategies queried in this manner as being motivational strategies but viewed them positively as things that created a more pleasant classroom atmosphere that promoted learning. Students suggested however the Korean system did not place an emphasis on learning but instead has such a pronounced focus on test scores that they did not seem to view test taking as a learning process, but as a completion-based task somewhat unrelated to acquisition of skills or knowledge. One student said she "could not imagine writing a story not SAT-related," and another student commented that English class was seen more as test preparation, than language learning. It could be argued that the students have a bifurcated view of education in which motivational macro strategies serve to increase learning whereas pressure whether derived from outside sources or systemic organization serves to improve performance on exams.

\section{Limitations}

The most obvious limitation possessed by this study is that it was conducted by NES teachers and this may have led the students to give a more positive account of NES teachers although it should be noted that statements about NES teachers were not universally positive. Additionally, the total number of students interviewed was a relatively small sample and not a randomized one but this also allowed the researchers to interview them for 
longer periods and ascertain more specific answers from the subjects.

\section{Further Study}

As with all things academic in nature additional study is required to create more actionable knowledge. The learning biographies of students are becoming increasingly diverse but it would be interesting to see comparisons between groups of students with differing experiences such as comparing students who learned entirely within a public-school setting to students who learned primarily through private school settings. Yet as stated previously the diversity of learning experiences afforded to students in Korea is changing and increasing rapidly.

One thing that may bear further investigation based on these findings is the extent to which NES teachers participate in the curriculum and test design of school systems within Korea and whether an increase in that role might lead to the greater inclusion of motivational macro strategies in classrooms.

\section{References}

Authors. (2017). Korean University Students' Perceptions of Teacher Motivational Strategies. International Journal of Learning, Teaching and Educational Research, 16(9). https://doi.org/10.26803/ijlter.16.9.3

Bravo, Jorge Cevallos, Eder A. Intriago, Jhonny Villafuerte Holguin, Gustavo Molina Garzon, \& Luis Ortega Arcia. (2017). Motivation and Autonomy in Learning English as Foreign Language: A Case Study of Ecuadorian. College Students. English Language Teaching, 10(2), 100-113. https://doi.org/10.5539/elt.v10n2p100

Cheng, H. F., \& Dörnyei, Z. (2007). The use of motivational strategies in language instruction: The case of EFL teaching in Taiwan. Innovation in Language Learning and Teaching, 1, 153-174. https://doi.org/10.2167/illt048.0

Dornyei, Z. (1994). Motivation and motivating in the foreign language classroom. The Modern Language Journal, 78(iii), 273-284. https://doi.org/10.1111/j.1540-4781.1994.tb02042.x

Dörnyei, Z. (1998). Motivation in second and foreign language learning. Language Teaching, 31(3), 117-135. http://dx.doi.org/10.1017/S026144480001315X

Dörnyei, Z. (2001a). Motivational Strategies in the Language Classroom. Cambridge: Cambridge University Press. https://doi.org/10.1017/CBO9780511667343

Dörnyei, Z. (2001b). Teaching and Researching Motivation. Harlow: Pearson Education Limited. https://doi.org/10.2307/3588444

Dörnyei, Z. (2009). The L2 motivational self system. In Z. Dörnyei \& E. Ushioda (Eds.), Motivation, language identity and the L2 self (pp. 9-42). Clevedon, England: Multilingual Matters. https://doi.org/10.21832/9781847691293-003

Dornyei, Z., \& Kubanyiova, m. (2014). Motivating learners, motivating teachers: Building vision in the language classroom. Cambridge: Cambridge University Press. https://doi.org/10.14746/ssllt.2013.3.3.7

Guillauteaux, M. J., \& Dörnyei, Z. (2008). Motivating Language Learners: A Classroom-Oriented Investigation of the Effects of Motivational Strategies on Student Motivation. Tesol Quarterly, 42(1), 55-77. https://doi.org/10.1002/j.1545-7249.2008.tb00207.x

Guilloteaux, M. J. (2013). Motivational strategies for the language classroom: Perceptions of Korean secondary school English teachers. System, 41(1), 3-14. https://doi.org/10.1016/j.system.2012.12.002

Jacques, S. R. (2001). Preferences for instructional activities and motivation: A comparison of student and teacher perspectives. In Z. Dörnyei \& R. Schmidt (Eds.), Motivation and second language acquisition. Honolulu: University of Hawaii Second Language Teaching and Curriculum Center. https://doi.org/10.2307/3588443

Maeng, U., \& Lee, S. M. (2015). EFL teachers' behavior of using motivational strategies: The case of teaching in the Korean context. Teaching and Teacher Education, 46, 25-36. https://doi.org/10.1016/j.tate.2014.10.010

Papi, M., \& Abdollahzadeh, E. (2012). L2 teacher motivational practice, student motivation and possible L2 selves: An examination in the Iranian EFL context. Language Learning, 62(2), 571-594. https://doi.org/10.1111/j.1467-9922.2011.00632.x

Ushioda, E. (2013). Motivation and ELT: Global issues and local concerns. In E. Ushioda (Ed.), International perspectives on motivation: Language learning and professional challenges (pp. 1-17). London: Palgrave Macmillan. https://doi.org/10.1057/9781137000873_1 
Veenman, Simon. (1984, Summer). Perceived Problems of Beginning Teachers. Review of Educational Research, 54(2), 143-178. https://doi.org/10.3102/00346543054002143

Yeo, K. (2017). Perceptions on Motivational Strategies in the Korean EFL Setting: Three Voices of Korean Instructors, Native English Speaking Instructors, and Their Learners. Contemporary Grammar Studies, 94, 99-133. https://doi.org/10.14342/smog.2017.94.99

\section{Copyrights}

Copyright for this article is retained by the author(s), with first publication rights granted to the journal.

This is an open-access article distributed under the terms and conditions of the Creative Commons Attribution license (http://creativecommons.org/licenses/by/4.0/). 